\title{
DOMINACIÓN, RESISTENCIA Y TECNOLOGÍA: LA OCUPACIÓN INCAICA EN EL NOROESTE ARGENTINO
}

\author{
DOMINATION, RESISTANCE AND TECHNOLOGY: \\ THE INKA OCCUPATION IN NORTHWEST ARGENTINA
}

\author{
Luis R. González* y Myriam N. Tarragó**
}

\begin{abstract}
La anexión al Tawantinsuyu implicó profundas transformaciones para las organizaciones sociales que poblaban el noroeste argentino. Es probable que las aspiraciones del estado cuzqueño por imponer sus pautas políticas, económicas e ideológicas hayan colisionado con los principios vigentes en la región, en particular en aquellas áreas en donde se habían desarrollado sociedades complejas con eficientes sistemas de producción material y simbólica. En el presente trabajo exploramos la articulación de la administración estatal con las organizaciones del sur del valle de Yocavil, a partir de los cambios y continuidades en la producción de alfarería y de metales y en las prácticas ceremoniales. Al respecto, planteamos que la dominación incaica en la región de estudio adquirió matices resultantes no sólo de los intereses específicos del poder cuzqueño, sino también de las cualidades organizativas de los sistemas locales y de las estrategias de resistencia desplegadas en el proceso.
\end{abstract}

Palabras claves: Estado incaico, valle de Yocavil, dominación y resistencia, noroeste argentino.

The annexation to Tawantinsuyu involved deep transformations of northwestern Argentine social organizations. It is likely that the Cuzqueñan state aspirations to impose its own political, economical, and ideological rules had clashed with current regional principles, particularly in those areas where complex societies with efficient material and symbolical production systems were developed. In this study we explore the articulation of state administration and southern Yocavil valley organizations through the changes and continuities in ceramic and metal production as well as ceremonial practices. We propose that Inka domination in the study area was not only the consequence of the specific interests of Cuzqueñan power, but also of the conditions of the local systems' organizational qualities and resistance strategies that were deployed during this process.

Key words: Inka state, Yocavil valley, domination and resistance, northwest Argentina.

La anexión del noroeste argentino (NOA) al Tawantinsuyu conllevó grandes transformaciones para las comunidades de la región, a partir de la imposición de nuevas pautas políticas, económicas y sociales. Ha sido subrayada la flexibilidad de los administradores incaicos para adecuar los proyectos del estado a las realidades de las diferentes áreas incorporadas al imperio, pero menor espacio se ha otorgado a la discusión de los mecanismos de resistencia que podrían haber desplegado las sociedades locales. La dominación implicó edificar un sistema de representaciones que integrara el mosaico cultural del territorio, institucionalizara la estructura de poder y divulgara las normas a las que debían ajustarse los sujetos del estado. Cabría esperar, no obstante, que los modos y resultados de la imposición de la ideología estatal mostraran una amplia variabilidad, sobre todo en espacios tan alejados del poder central como el NOA y más aún en aquellas áreas ocupadas por formaciones sociales con desigualdad institucionalizada y una superestructura que naturalizaba las diferencias.

El objeto de este artículo es repasar, en primer lugar, algunos aspectos de los cambios y continuidades en las producciones metalúrgica y alfarera en el valle de Yocavil meridional, provincia de Catamarca, durante la época de dominio incaico. Consideramos que el proceso productivo de la cultura material entrañó relaciones sociales fundadas en concretas condiciones materiales de existencia y que la tecnología fue mucho más que los recursos disponibles y los procesos de transformación aplicados. Involucró, ante todo, contextos socioculturales que legitimaron y determinaron qué producir y cómo hacerlo, al igual que el destino y las prescripciones de uso de los productos (González 2002a). Para el caso de estudio, el análisis de la producción de ciertos bienes de prestigio puede

\footnotetext{
* Depto. Cs. Antropológicas, Fac. Filosofía y Letras, Universidad de Buenos Aires. Moreno 350 (1091). Buenos Aires. Argentina.

** CONICET, Museo Etnográfico, Universidad de Buenos Aires. Moreno 350 (1091). Buenos Aires. Argentina.
} 
proporcionar elementos para acercarnos al conflicto del enfrentamiento entre las ideologías hegemónica y subalterna. En segundo lugar y teniendo en cuenta el papel protagónico que los arquitectos del imperio le otorgaron a la planificación del espacio social como instancia fundacional de un nuevo orden (Gallardo et al. 1995), hacemos referencia a las modificaciones en las estructuras ceremoniales que materializaban los principios que regulaban el devenir cotidiano de las sociedades andinas.

\section{La Dinámica Histórica del Valle de Yocavil Meridional}

El sector meridional del valle de Yocavil (Figura 1) constituyó uno de los paisajes más densamente poblados del NOA en los momentos prehispánicos que se extienden entre los siglos IX y XVI. Numerosos asentamientos de distinta envergadura y características se desarrollaron evidenciando una creciente tasa demográfica sostenida por la explo-

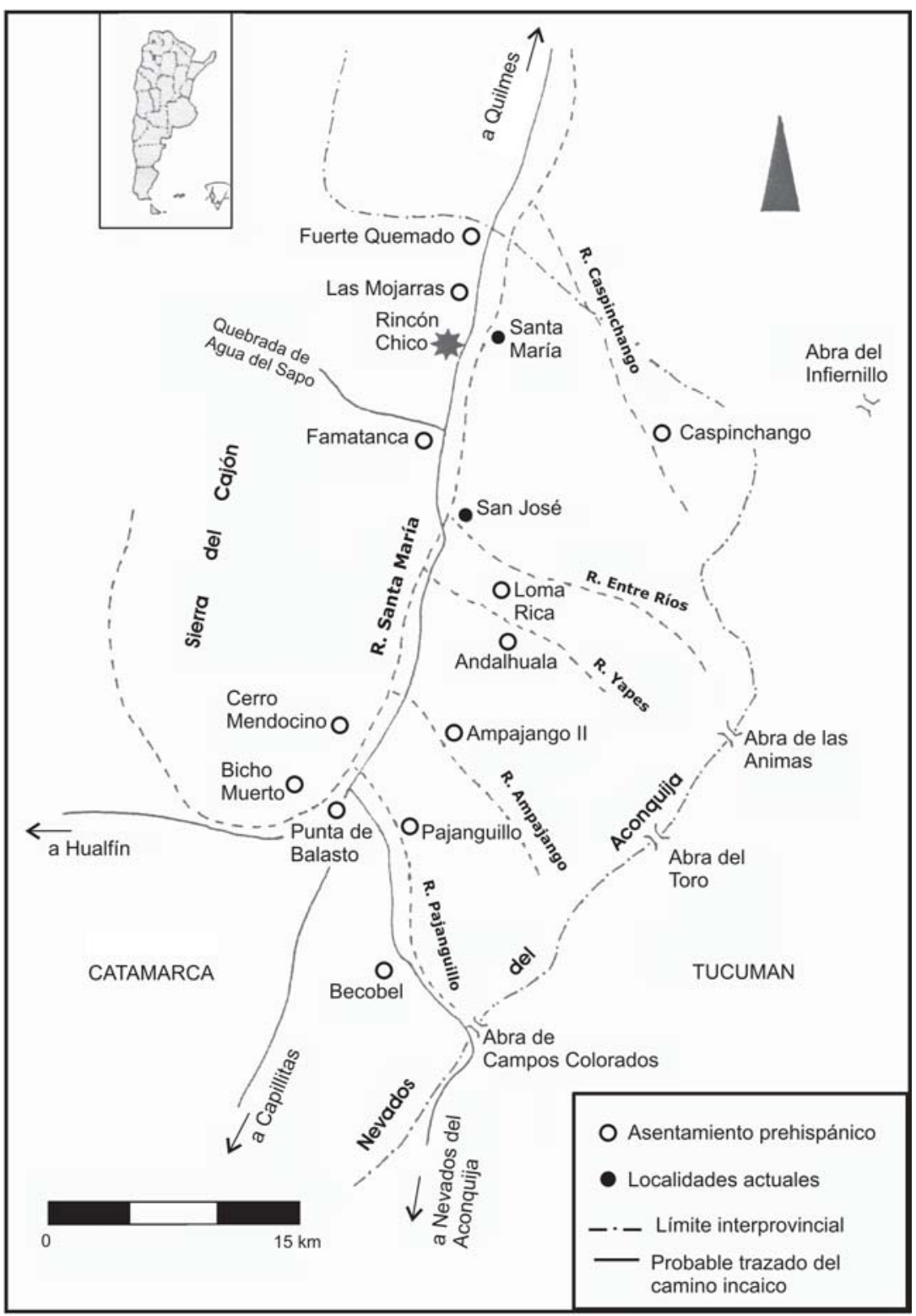

Figura 1. Distribución de evidencias incaicas en el sur del valle de Yocavil (González y Tarragó 2002a).

Sites with Inca cultural material in the south of the Yocavil valley (González y Tarragó 2002a). 
tación agropecuaria y la caza y recolección (González y Tarragó 2002a). La consolidación de sociedades jerarquizadas articuló a los asentamientos del valle en diferentes niveles, habiéndose propuesto que el poblado de Rincón Chico asumió la primacía dentro de un sistema de complementariedad funcional para la obtención directa de los recursos básicos para la subsistencia (Tarragó 1998:211; Tarragó y Nastri 1999:261-262). El asentamiento habría alcanzado su máxima expansión poco antes o en coincidencia con la llegada cuzqueña. De acuerdo a los fechados radiocarbónicos obtenidos, ello habría tenido lugar durante el primer cuarto del siglo XV (González y Tarragó 2002a). Considerando los intereses cuzqueños, la región exhibía algunas características ventajosas. Por un lado, era parte de un corredor que conectaba el corazón del imperio con sus dominios más australes, estando el fondo del valle recorrido por un tramo principal del capacñan. Por otro lado, las sofisticadas organizaciones productivas existentes (e.g., los sistemas agrícolas y los talleres metalúrgicos) podían ser redimensionadas y reorientadas hacia los requerimientos estatales a bajo costo (Tarragó et al. 2001). La compleja organización sociopolítica vigente probablemente facilitó la aplicación de estrategias de dominación indirecta, a través de la captación de los líderes locales como agentes del estado.

Hasta hace pocos años, los registros sobre la presencia incaica en la región se limitaban a los asentamientos de Fuerte Quemado y Punta de Balasto. Recientemente dimos a conocer un conjunto de datos que sugieren que la ocupación imperial fue bastante más intensa que lo tradicionalmente reconocido pero con un reflejo arqueológico de alta variabilidad (Tarragó et al. 2001; González y Tarragó 2002a, 2003). Al respecto, propusimos que la diferencial densidad y calidad de las evidencias estaría indicando no sólo los objetivos específicos de los administradores estatales sino también las cualidades de la organización política y económica preexistente.

\section{La Producción Tecnológica Preincaica}

El incremento en la diferenciación social en las comunidades vallistas y en la escala de las interacciones a larga distancia auspició la producción de bienes de prestigio a cargo de operarios especializados. Además de su excelente factura técnica, estos bienes fueron enriquecidos con el surplus simbólico materializado, en el valle de Yocavil, en la conocida iconografía santamariana. La potencia del mensaje iconográfico queda evidenciada por la amplia dispersión surandina que alcanzaron estos materiales (véase Tarragó et al. 1997). El tratamiento y la combinación de los motivos iconográficos variaron de acuerdo al tipo de material tratado. En cerámica, fueron las urnas funerarias los objetos de mayor tamaño y donde las representaciones alcanzaron su mayor complejidad. Si bien se trata de piezas muy conocidas (Figura 2), corresponde resaltar su excelente factura y la compleja decoración pintada y modelada (Tarragó 2000:282-284).

La alfarería santamariana se presenta en los asentamientos del valle de Yocavil acompañada por otro tipo, denominado Famabalasto Negro Grabado, en proporciones minoritarias pero regulares y que ha sido considerado originario de la región (Palmarzuck y Manaziewicz 2001). Esta cerámica, conocida sobre todo a partir de escudillas, presenta atributos tecnológicos muy diferentes a los de las urnas. El color de la superficie y de la matriz es oscuro, las pastas son de granulometría muy fina y se habrían utilizado para su manufactura materias primas y técnicas de cocción particulares. También la forma de plasmar los elementos iconográficos y su selección y distribución fue muy distinta a la empleada en la alfarería santamariana clásica. En el Famabalasto Negro Grabado se utilizó la incisión en la pasta cruda y los motivos predominantes son los geométricos, registrándose también algunos figurativos. La decoración fue dispuesta, casi siempre, en forma de guardas (Figura 3), ubicándose, en las escudillas, en los bordes de las piezas. $\mathrm{Al}$ respecto, se señalaron similitudes entre estos motivos y los de las campanas ovales y discos de bronce, planteándose que este tipo cerámico representa un puente simbólico y material entre los ceramistas y los metalurgistas santamarianos y que habría estado relacionado con desempeños ceremoniales, compartiendo el escenario ritual con los bronces (González y Tarragó 2002b).

En el caso de los metales, los temas del estilo santamariano se concentran en unos pocos motivos dominantes plasmados en líneas en relieve, situación que no derivaría sólo de dificultades técnicas para tratar los materiales sino también de una diferencia en el valor simbólico de las piezas de metal respecto de las de cerámica (A. González 1998:161). 

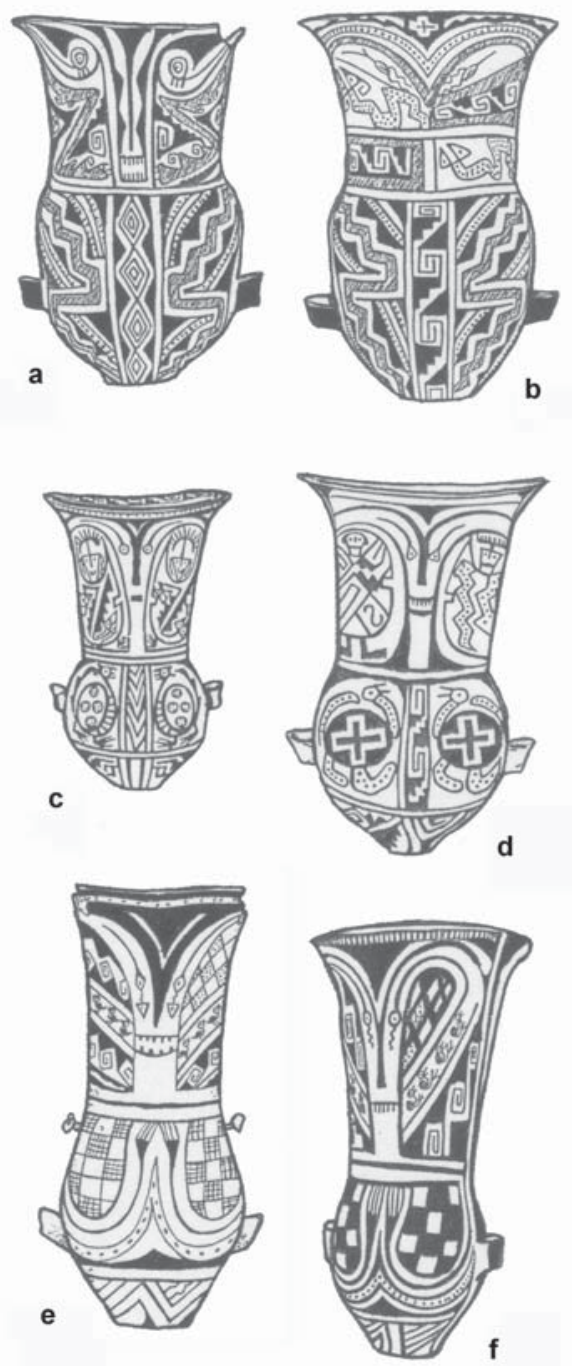

Figura 2. Urnas santamarianas: (a) Fase II, altura $51 \mathrm{~cm}$; Quilmes, Catamarca. Col. Museo de La Plata (MLP) Nº18 (Bruch 1911: Figura 32), (b) Fase III, altura $59 \mathrm{~cm}$; Fuerte Quemado. MLP N 46 (Bruch 1911: Figura 95), (c) Fase IV, altura $61 \mathrm{~cm}$; Punta Balasto. Col. MLP No 4415 (González 1977: Figura 291), (d) Fase IV, altura $60 \mathrm{~cm}$; Punta de Balasto. MLP Col. Muniz Barreto (Márquez Miranda 1936: Figura 6), (e) Fase V, altura $64 \mathrm{~cm}$; Famabalasto, Cementerio VII, Urna 8. MLP 5400 (Cigliano 1958: Figura 12), (f) Fase V, altura $61 \mathrm{~cm}$. Fuerte Quemado. MLP No 41 (Bruch 1911: Figura 96).

Santamarianas funerary urns: (a) Phase II, height $51 \mathrm{~cm}$; Quilmes, Catamarca. Col. Museo de La Plata (MLP) No 18 (Bruch 1911: Figure 32), (b) Phase III, height $59 \mathrm{~cm}$; Fuerte Quemado. MLP No 46 (Bruch 1911: Figure 95), (c) Phase IV, height $61 \mathrm{~cm}$; Punta Balasto. Col. MLP No 4415 (González 1977: Figure 291), (d) Phase IV, height $60 \mathrm{~cm}$; Punta de Balasto. MLP Col. Muniz Barreto (Márquez Miranda 1936: Figura 6), (e) Phase V, height $64 \mathrm{~cm}$; Famabalasto, Cementerio VII, Urna 8. MLP 5400 (Cigliano 1958: Figura 12), (f) Phase V, height 61 $\mathrm{cm}$. Fuerte Quemado. MLP N 41 (Bruch 1911: Figure 96).

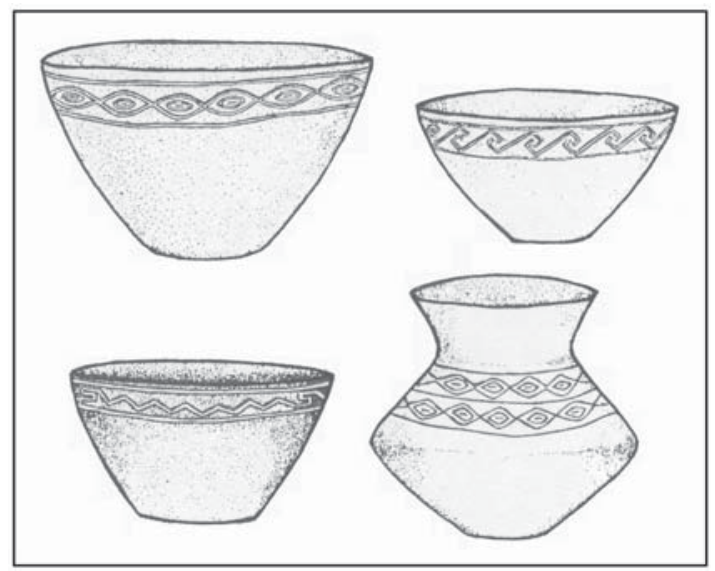

Figura 3. Alfarería Famabalasto Negro Grabado (alturas entre 15 y $22 \mathrm{~cm}$ ). Arriba izquierda MLP N ${ }^{\circ}$ 5340. Arriba derecha MLP $N^{\circ}$ 5352. Abajo izquierda MLP $N^{\circ}$ 5237; Abajo derecha MLP N $^{\circ}$ 5382. Famabalasto, Cementerio VII, cistas 5 y 6, respectivamente (Cigliano 1958 Lám. XIII y XIV).

Famabalasto engraved black pottery type (height between $15 y$ $22 \mathrm{~cm}$ ). Upper left MLP $N^{o} 5340$. Upper right MLP $N^{o} 5352$. Below left MLP $N^{\circ}$ 5237. Below right MLP $N^{o} 5382$. Famabalasto, Cementerio VII, cists 5 and 6, respectively (Cigliano 1958 Lám. XIII y XIV).

Los objetos de bronce más sobresalientes son las placas, las campanas ovales y las hachas con mango incorporado. Esta trilogía de objetos fue parte sustancial de la parafernalia que acompañaba al ceremonialismo religioso de las sociedades tardías de la región, el cual incluía sacrificios y cercenamiento de cabezas (A. González 1983:268, 1992:248). Los rostros o cabezas humanas son los motivos más habituales de los bronces. También aparecen representaciones zoomorfas y, con menor frecuencia, figuras humanas (Figura 4).

El valle de Yocavil parece haber conformado un laboratorio de innovación metalúrgica durante las épocas prehispánicas tardías. Los datos más ilustrativos provienen de las investigaciones que se realizan en el sitio 15 de Rincón Chico, donde operó un taller metalúrgico cuya escala de producción creció al ritmo del proceso sociopolítico regional. Durante las extensas excavaciones realizadas se recuperaron y registraron evidencias correspondientes a todas las etapas del proceso de producción metalúrgica (L. González 1992, 1997, 2001, 2002b, entre otros). El estudio de las evidencias y doce fechados radiocarbónicos permitieron establecer las características de la organización productiva y sus transformaciones históricas. Desde los comienzos de la ocupación se elaboraron obje- 


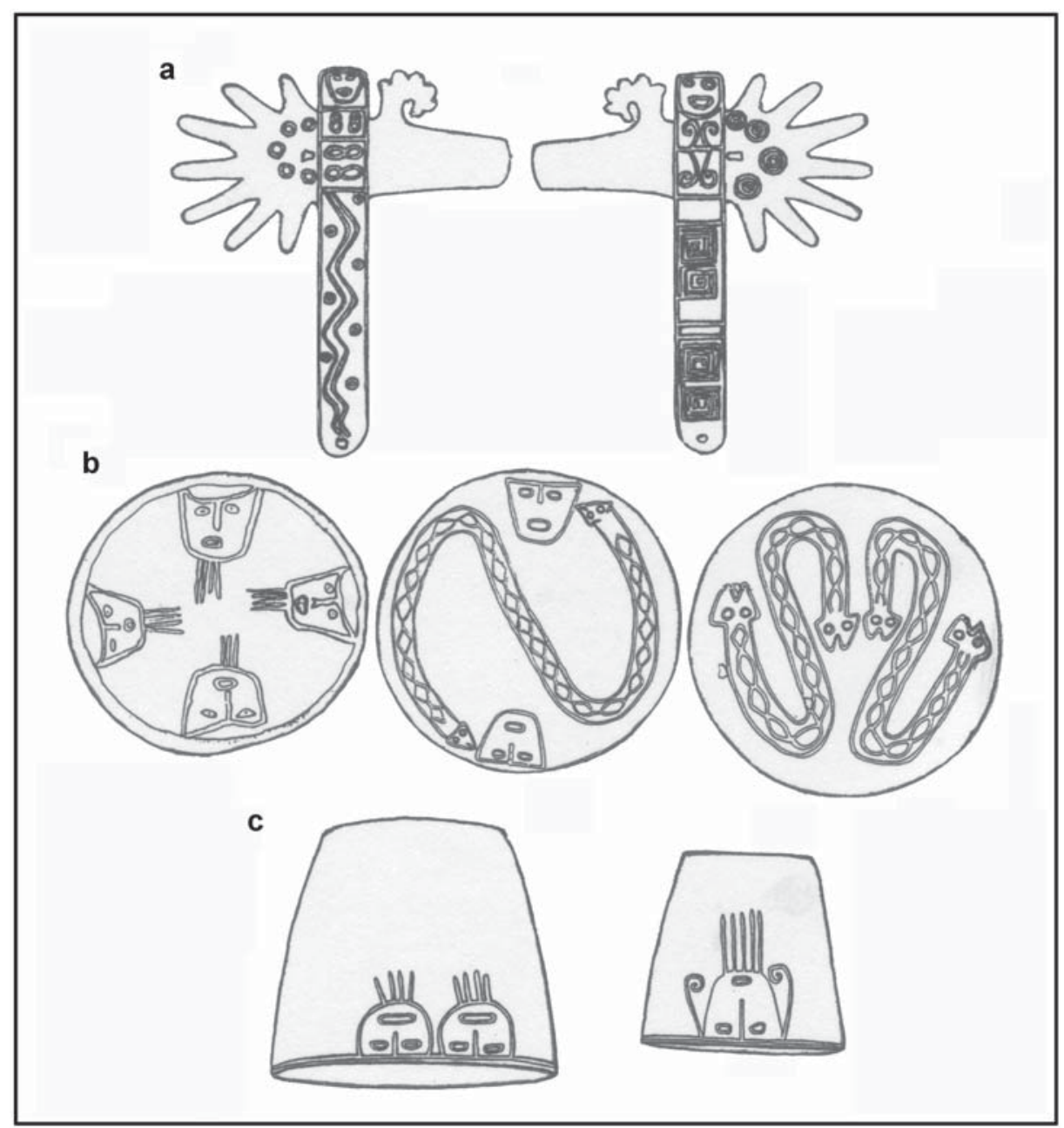

Figura 4. Discos, campanas y hachas de bronce: (a) anverso y reverso de un hacha, altura $31 \mathrm{~cm}$, Museo Etnográfico (ME) No 28042, (b) discos, diámetros entre 23 y $27 \mathrm{~cm}$, Izquierda, ME No 1, Pampa Grande, Centro, ME No 4124, Salta, Derecha Museo de Tilcara No 665, Belén, (c) campanas ovales, alturas 26 y 16 cm, izquierda valle Calchaquí (Márquez Miranda 1946, Figura 105), derecha Río Tala (Ambrosetti 1904:259, Figura 66).

Disks, bells, and bronze axess: (a) obverse and reverse of an axe, height $31 \mathrm{~cm}$, Museo Etnográfico (ME) $N^{o}$ 28042, (b) disks, diameter between 23 y 27 cm, left, $M E N^{o} 1$, Pampa Grande, center, ME $N^{o} 4124$, Salta, right Museo de Tilcara $N^{o} 665$, Belén, (c) oval shape bells, height 26 y $16 \mathrm{~cm}$, left Calchaquí valley (Márquez Miranda 1946, Figure 105), right Tala river (Ambrosetti 1904:259, Figure 66).

tos de bronce estañífero, fundiendo en crisoles que eran calentados en fogones. De acuerdo a los fragmentos de refractarios recuperados, se manufacturaban, además de pequeños útiles, grandes discos y campanas ovales.

\section{De Piedras y Colores}

El aumento de la complejidad sociopolítica de las comunidades vallistas fue acompañado por un incremento similar en la escala y el grado de formalización de las prácticas ceremoniales. En este proceso, el conocimiento esotérico fue siendo capitalizado por un sector social minoritario que, al arrogarse el papel de intermediario entre la comunidad y las deidades, se transformó en estratégico para las operaciones económicas y políticas de las elites gobernantes con las cuales estaban asociadas (González 2001). La intervención de exclusivos elementos rituales, al tiempo que acreditaba la 
propiedad del aquel conocimiento esotérico, actuaba por su excelencia como emblema de distinción entre los individuos. Las investigaciones acerca de las características de las estructuras cúlticas de las épocas prehispánicas tardías en el NOA no han sido numerosas (cf. A. González 1983:239), pero los datos disponibles indican que, en algunos casos, se llegó a incorporar rasgos del paisaje al universo social. Un ejemplo proviene del mismo poblado de Rincón Chico. En el área nuclear de las construcciones, una quebrada fue cortada a distintas alturas con líneas de muros levantadas con rocas de diferentes colores (Tarragó y González 2002). La disposición de estos muros hizo que las alternativas de acceso hacia los sectores altos estuvieran pautadas y claramente restringidas. Algunas de las construcciones parecen haber sido diseñadas para servir de escenario a los oficiantes del culto, mientras que otras enmarcaron espacios para la congregación de los asistentes. El área posibilitaba la reunión de magnitudes relativamente considerables de público y su topografía le otorgó condiciones ideales para la propagación vertical tanto de la voz humana como del sonido de instrumentos musicales de carácter ritual, como las mencionadas campanas de bronce.

Fuentes etnohistóricas (González 1983:235) y arqueológicas (Tartusi y Núñez Regueiro 1993; González y Cabanillas 2004) sugieren que prácticas rituales sistemáticas estuvieron organizadas en torno a grandes peñascos naturales, en ocasiones labrados y casi siempre rodeados por plataformas de piedras, en algunos de los cuales se habrían practicado sacrificios y quema de ofrendas. Estos peñascos, llamados huanca, acreditaban una polivalencia simbólica. Por un lado eran reverenciados a imagen de las montañas, las cuales asumían importancia en el control de los fenómenos meteorológicos y, además, eran residencia de la multifacética Pachamama y de los antepasados de la comunidad. Por otra parte, las huanca operaban como representaciones de los ancestros y conformaban no sólo puentes hacia el más allá, sino también monumentos que insertaban a la comunidad en una trayectoria histórica, articulándola con un pasado que legitimaba la propiedad del terruño (Pérez Gollan 2000). En Rincón Chico, un cinturón de voluminosos peñascos se distribuye en el quiebre de pendiente del cerro que alberga el poblado aglomerado. Se trata de grandes bloques derrumbados de las laderas y que fueron integrados al paisaje social mediante la construcción de plataformas semicirculares de bloques de piedras. Es probable que, mientras la quebrada del Puma constituía un escenario ritual de alcance comunitario amplio, las diferentes huanca del poblado conformaran mochaderos de distintas fracciones sociales.

Las excavaciones exploratorias realizadas en torno a uno de estos peñascos (ML 25; Figura 5) permitieron recuperar evidencias relacionadas con enterratorios y sacrificios de camélidos. Unos 300 $\mathrm{m}$ al sur se encuentra el Sector XIII del Sitio 1, donde se distribuyen grandes huanca de formas prismáticas, cinco de ellas con signos de labrado. Las plataformas adosadas fueron levantadas con rocas seleccionadas por su color, en particular bloques de cuarzo blanco y de feldespato rosado. Las excavaciones realizadas en el peñasco ML 39 dieron a luz restos óseos correspondientes a dos adultos y un niño, este último inhumado en una urna funeraria Fase V, considerándose probable que correspondan a individuos sacrificados. Otro de los peñascos investigados fue el ML 35 (Figura 6), cuya plataforma de piedras incluía en su parte central una roca de granito de forma piramidal alargada, pulida y de una altura de $0,85 \mathrm{~m}$, que fue cuidadosamente erigida calzándola con piedras pequeñas. Además, fue recuperado un fragmento de campana oval de bronce, instrumento que, según informaron los estudios técnicos, se habría fracturado in situ en ocasión de su uso (González y Cabanillas 2004:242).

\section{Alfarería y Metalurgia bajo la Dominación Estatal}

Las urnas funerarias santamarianas, a partir de la Fase IV, fueron consideradas dentro de los materiales de estilos locales que sufrieron modificaciones. Respecto de momentos previos, las urnas presentan cambios en las formas y proporciones y en la distribución de los motivos iconográficos. Por ejemplo, los cuerpos se estrechan, los cuellos se alargan y comienzan a aplicarse cabecitas modeladas (Figura 2). No obstante, teniendo en cuenta la alta susceptibilidad de la alfarería para reflejar cambios tan dramáticos como los esperables a partir de la imposición de las condiciones de la organización estatal, dichas modificaciones aparecen como poco significativas. Cabe recordar que elementos reconocidos en la iconografía incaica (ta- 


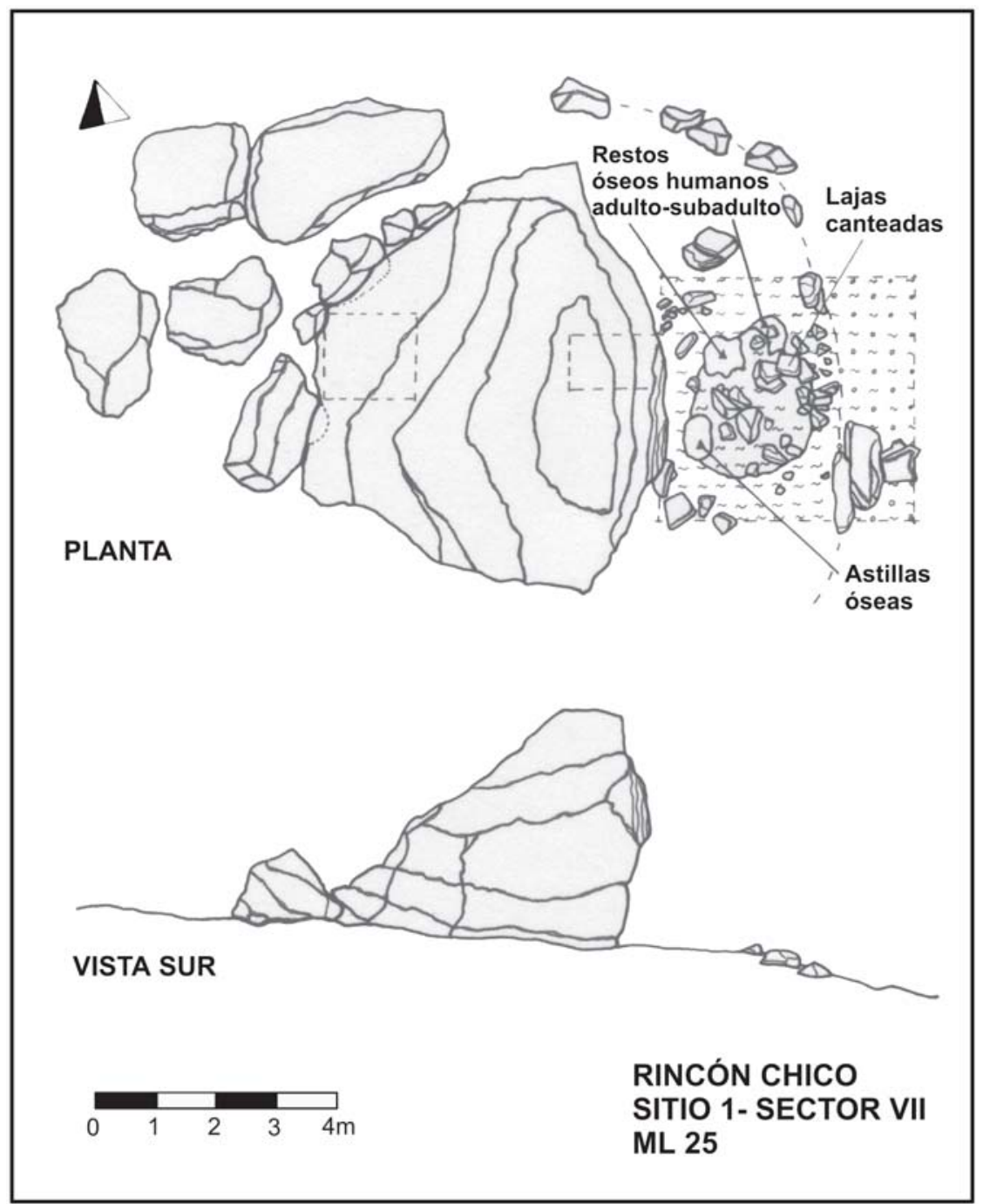

Figura 5. Rincón Chico, sitio 1, sector VII. La Huanca ML 25.

Rincón Chico, site 1, sector VII. La Huanca ML 25.

les como dameros y rombos encadenados) ya formaban parte de la paleta santamariana, habiéndose planteado que uno de los motivos incorporados a partir del dominio imperial en la región sería el de los "polluelos" de las urnas santamarianas Fase V (González y Tarragó 2002b). Tal vez una de las mayores transformaciones esté dada por las "urnas piriformes" decoradas con una guarda de serpientes bicéfalas en el vientre del cántaro y triángulos llenos en el cuello, las que fueran identificadas como "estilo mixto santamarianoinca” (Tarragó et al. 1997:238, Figura 14), toda vez que la forma parece ser una "versión libre" de los grandes aribaloides cuzqueños. Los estudios tec- nológicos pusieron de manifiesto, por otra parte, una continuidad en los procedimientos de manufactura de las piezas.

En cuanto a la alfarería Famabalasto Negro Grabado, tenemos evidencias que el estilo se desarrolla desde el siglo X (Tarragó 1998:227, 229¹), pero, a partir de la dominación incaica, las piezas trascienden su ámbito de circulación y aparecen en contextos externos al valle de Yocavil (Palmarzuck y Manaziewicz 2001): se las ha reconocido en instalaciones estatales como Potrero Chaquiago (Andalgalá), El Shincal (valle de Hualfín) y Potrero de Payogasta (valle Calchaquí norte), siendo probable que esta distribución responda a la in- 


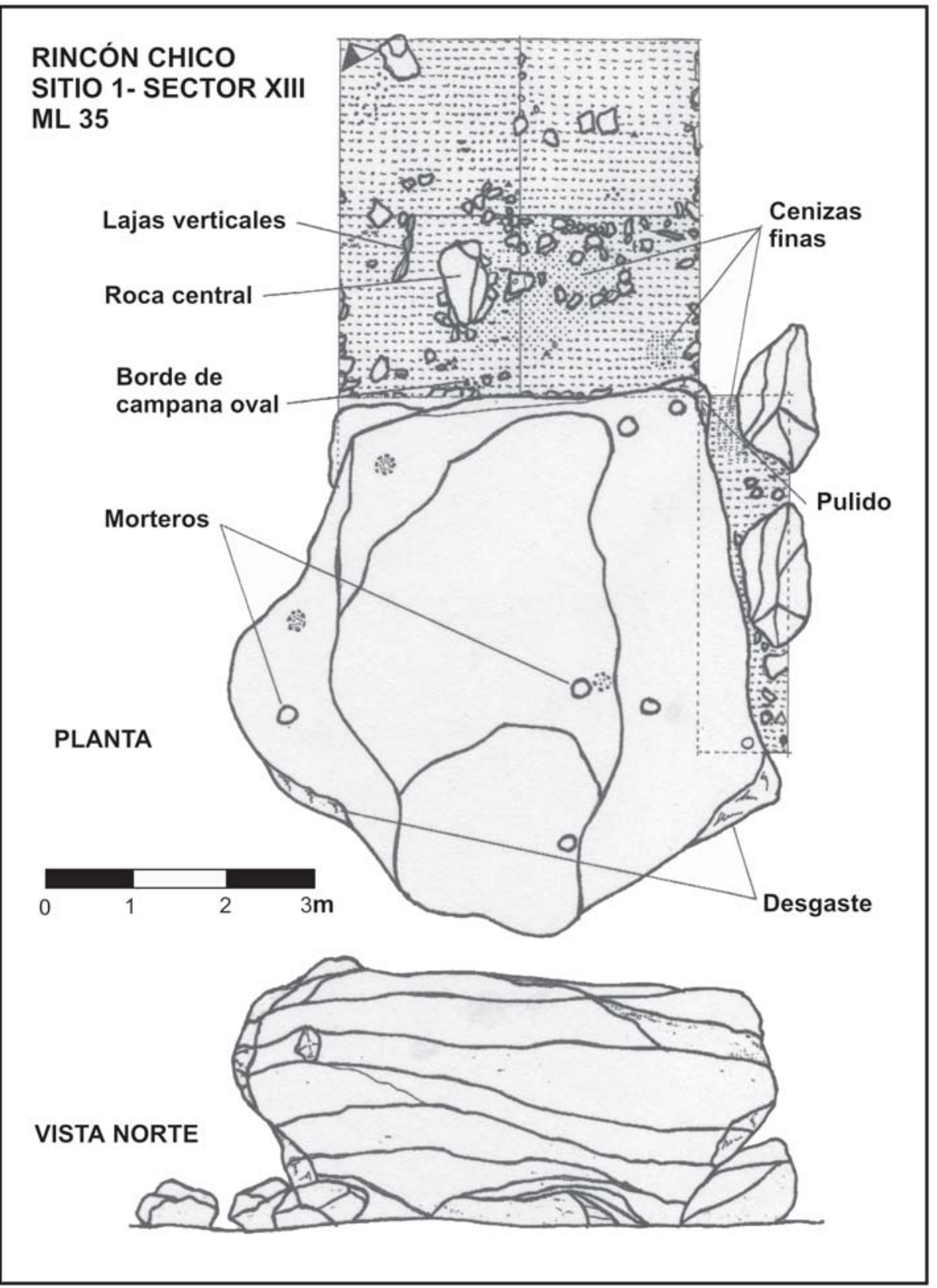

Figura 6: Rincón Chico, sitio 1, sector XIII. La Huanca ML 35.

Rincón Chico, site 1, sector XIII. La Huanca ML 35.

tervención de los administradores cuzqueños. Más allá de esto, las características tecnológicas y decorativas de las piezas tardías mantuvieron identidad con las de épocas preincaicas.

En lo que se refiere a los estilos Inka Provincial, es muy baja su presencia en el seno del área definida al sur de Fuerte Quemado, tanto a partir de materiales de superficie recuperados en las amplias prospecciones efectuadas como en excavación. Nunca supera el $2 \%$ de especímenes en los sitios donde aparece. En la franja occidental se limita a fragmentos de "aribaloides" rojo pulidos de pasta local y algunos platos, mientras que al oriente, en las laderas del Aconquija y, sobre todo, en el 
tambo de Punta de Balasto, aparecen otras variedades, como Inka cuzqueño, Inka Paya e Inka Pacajes.

Los administradores estatales encontraron talleres metalúrgicos dotados con mano de obra especializada y que manejaban con soltura el bronce estañífero, considerado como la aleación imperial por excelencia (Earle y D'Altroy 1989:203; Lechtman 1978:511). En el taller del sitio 15 de Rincón Chico, la dominación implicó un aumento en la escala de producción. En tal sentido: a) se habilitó un nuevo espacio para las actividades; b) se promovió el uso de hornillos de fundición del tipo huayra; y c) se incrementó la frecuencia de eventos de fundición y el volumen de procesamiento de materiales. Los espacios de trabajo hasta ese momento en operación en el taller no fueron desactivados sino reasignados funcionalmente para participar en la nueva cadena operativa (González 2001, 2002b:63-64).

El taller quedó ubicado a la vera de uno de los tramos troncales del camino imperial que atravesaba la zona y que unía importantes postas como Quilmes, Fuerte Quemado, Punta de Balasto y Shincal. Esta situación aseguraba una eficiente movilización de materias primas minerales y la evacuación de productos desde el taller para su eventual distribución regional o extrarregional. De no menor importancia, todos los aspectos de la producción metalúrgica quedaban sujetos al control estatal. La asociación entre talleres metalúrgicos y caminos imperiales ha sido verificada también en asentamientos vecinos, como Las Mojarras y Fuerte Quemado (González y Tarragó 2002a). Una modificación significativa impuesta por la administración incaica parece haber sido la demanda de lingotes de diversos tamaños, algunos de cuyos restos fueron registrados en el sitio 15 en vinculación con evidencias de procesamiento de oro (Figura 7). Es posible que parte de los lingotes se relacionaran con el traslado de metal precioso hacia el Cuzco, como dejan entrever algunos documentos etnohistóricos (Montes 1959:88-89). Sin embargo, el procesamiento del oro fue incorporado como una más de las tareas a desarrollar en el taller. Más allá de incrementar la escala de producción metalúrgica en el taller del sitio 15, el incario no parece haber incorporado modificaciones técnicas de peso. A lo largo de la secuencia de ocupación del sitio, los modos de preparación de moldes y crisoles respondieron a las mismas normas técnicas. La dosificación del estaño en los bronces se mantuvo en los niveles de épocas anteriores, no registrándose evidencias de una estandarización en ese aspecto (González 2001, 2002b:64). De igual modo, las elaboradas piezas del repertorio local, como discos y campanas, siguieron fabricándose. Tanto los objetos procedentes de la región como los motivos grabados en los moldes recuperados indican que el estilo decorativo santamariano en los metales continuó vigente.

\section{El Alcance de las Nuevas Tendencias Ceremoniales}

Como en la cultura material, la ocupación incaica en el sur del valle de Yocavil se manifestó con dispar intensidad en el modo de intervención sobre las prácticas ceremoniales locales y la infraestructura inherente a ellas. Se advierten dos situaciones polares. Un ejemplo de una intervención de cierta envergadura fue registrado en el asentamiento de Ampajango II, ubicado sobre una terraza junto al río homónimo (Figura 1). El poblado parece haber tenido una marcada orientación hacia la producción agrícola y la muestra de alfarería en superficie, compuesta por tipos Gris Pulido, Famabalasto Negro sobre Rojo, Santa María bicolor, Belén-Santa María, Quilmes Rojo Grabado e Inka, entre ellos Inka Paya y Cuzco policromo, sugiere una prolongada ocupación.

En el sector IV del asentamiento se registró una plaza delimitada por un muro y cuya superficie fue despejada por intensos trabajos de despedrado (Figura 8). En la esquina noroeste de la plaza se encuentra una estructura presidida por un gran peñasco que fue enmarcado por líneas de pircas que, probablemente, formaban plataformas escaleradas. La cara sur del peñasco, orientado hacia la plaza y hacia las cumbres nevadas de la cadena del Aconquija, presenta dos líneas de plataformas de muros más prolijos, mostrando algunas de las piedras un canteado expeditivo. Hacia el norte y el este, el declive del terreno fue compensado con cinco hileras de piedra, habiéndose incluido, además, una especie de rampa que permite ascender a la cúspide plana de la gran roca. Durante un reconocimiento realizado en 1991 en la plaza, fue recuperado en superficie un liwi de bronce estañífe- 


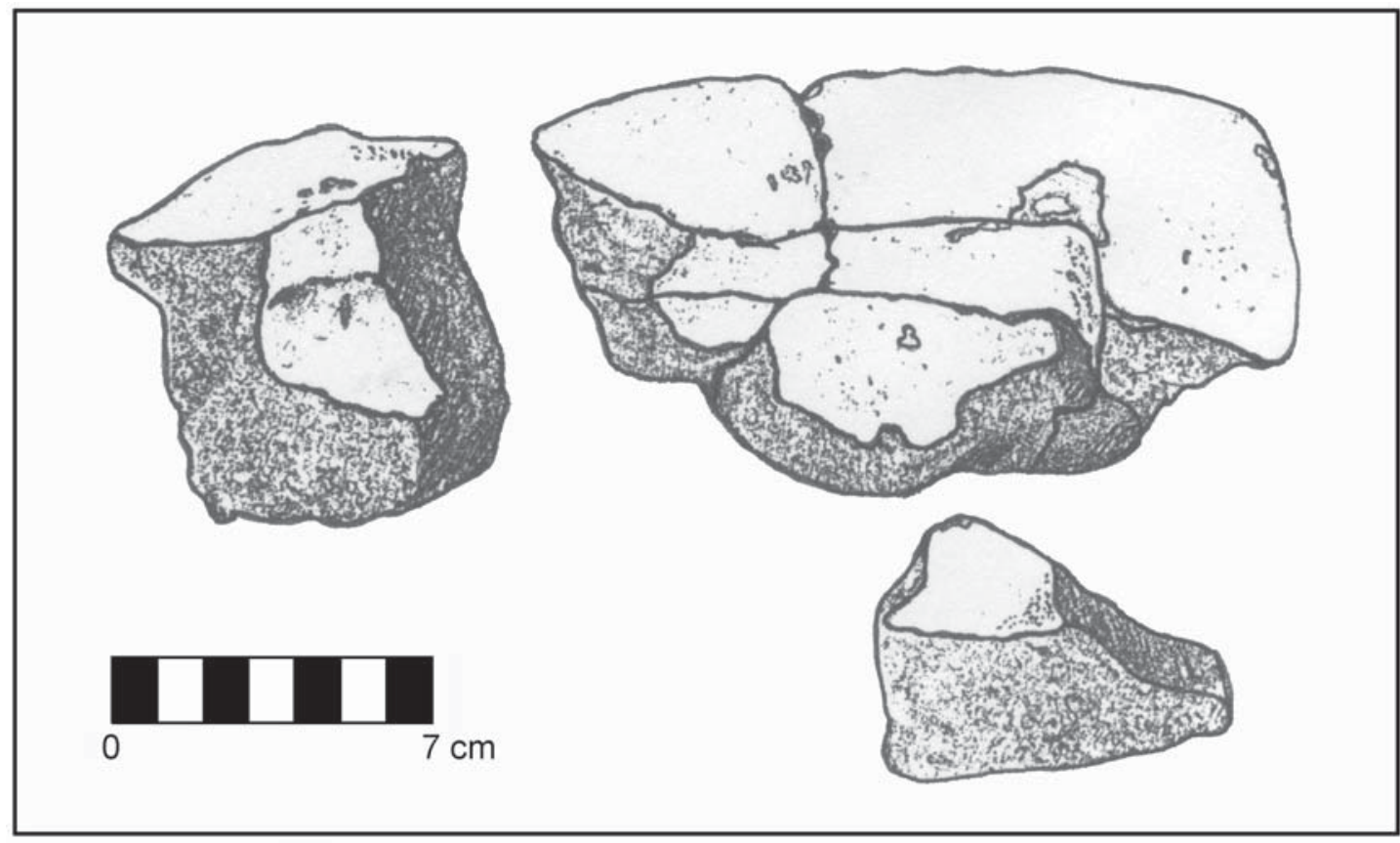

Figura 7. Molde de lingote del sitio 15 de Rincón Chico.

Ingot mold, site 15, Rincón Chico.

ro de clara raigambre incaica (González y Palacios 1996). En 2000 fueron excavadas dos cuadrículas exploratorias, ubicándose las superficies de ocupación, recuperándose una muestra cerámica con frecuencias similares a las de superficie y obteniéndose un fechado sobre carbón vegetal ${ }^{2}$. También fue registrado un fragmento de una cadenita de hierro, adscribible a momentos del contacto hispanoindígena (Tarragó et al. 2001).

En Ampajango II, la ocupación incaica implicó ciertas transformaciones, más visibles en sus cualidades espaciales, destacándose en tal sentido dos aspectos. En primer lugar, se ordenó la circulación tanto dentro del poblado como en sus accesos, a través de senderos, rampas y escalerados claramente pautados. Si bien estas vías de tránsito pudieron responder a los requerimientos de las actividades que se desarrollaban en el asentamiento, el entramado también dejó establecidos los movimientos autorizados y los prohibidos, al tiempo que diferenció las áreas de acceso público de aquellas de acceso restringido. En segundo lugar, se encararon algunas obras de remodelación que tanto eliminaron ciertas estructuras como produjeron otras. Es probable que las estructuras novedosas, al igual que las vías de circulación, operaran materializan- do en el espacio las condiciones imperantes sobre los sujetos del poblado. Sin embargo, debe subrayarse que tales remodelaciones se efectuaron mediante las técnicas constructivas autóctonas y sólo unos pocos detalles de la arquitectura imperial, por ejemplo las piedras desbastadas, se aplicaron en lugares específicos.

Es probable que la presencia incaica en el poblado aparejara una transformación y aumento en la escala del ceremonialismo vinculado tanto con los ritos de fertilidad como con la integración del espacio a la organización estatal. La gran roca que preside la plaza del sector IV fue transformada en un ushnu con características conocidas en otras instalaciones del territorio del Tawantinsuyu (e.g., Hyslop 1990:69-83; Dearborn et al. 1998). El peñasco debió constituir, en épocas previas, una huan$c a$ dedicada al complejo ancestros-montañas-fertilidad. Los administradores cuzqueños habrían aprovechado la sacralidad del monumento, lo redimensionaron y, sin que perdiera, tal vez, relación con las divinidades tutelares de la región, le otorgaron una mayor significación política, sustrayendo del control local su potencial simbólico e incorporándolo a la estructura religiosa estatal (Tarragó et al. 2001). A tal fin, se rodeó al peñasco con una 


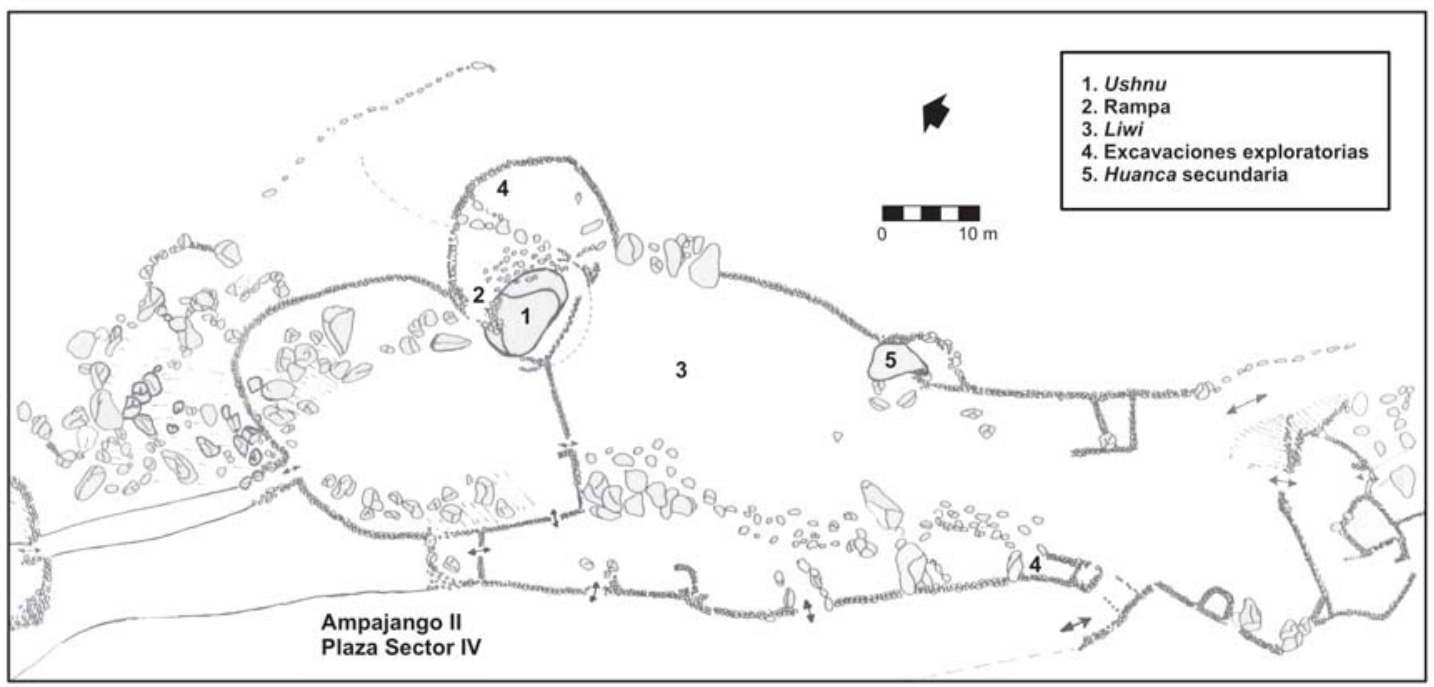

Figura 8. Plaza del sector IV de Ampajango II.

Square of sector IV at Ampajango II.

estructura de líneas de piedras, muchas de ellas con signos de trabajo de desbaste. El control impuesto sobre el escenario ceremonial pudo implicar, de igual modo, la remodelación del espacio que ocupaba la plaza para crear, al mismo tiempo, áreas de congregación, para un público limitado, y de segregación. A estas características del asentamiento se suma un "reducto de cumbre" establecido mediante un muro que circunvala la cima de la cercana Loma Redonda de Ampajango, un rasgo topográfico muy visible en el sudeste del valle de Yocavil.

En el otro extremo del espectro, la dominación aparejó modificaciones de menor cuantía, siendo Rincón Chico el caso más ilustrativo. En el sitio 14 de la localidad fue estudiado un probable contexto de elaboración de chicha en cantidades superiores a las requeridas por una unidad doméstica, habiéndose planteado que las actividades estuvieron vinculadas con la realización de festejos periódicos a través de los cuales se renovaban las relaciones de poder entre el estado y los líderes locales (Tarragó et al. 1999:423). No obstante, no se realizaron modificaciones arquitectónicas sino que siguieron utilizándose las instalaciones existentes. Tampoco el vasto escenario ceremonial del poblado central en la quebrada antes descrita parece haber sido intervenido, aunque no puede descartarse que, tal vez, se realizaran algunas obras destinadas a convocar a un mayor número de asistentes y que se incorporaran núcleos arquitectóni- cos con espacios trapezoidales del tipo kancha, en el pie del cerro, como en los sitios 2, 3 y 10 de Rincón Chico. A la llegada del incario, la quebrada probablemente constituía un centro de peregrinación que convocaba a poblaciones cercanas y la administración cuzqueña, lejos de combatir las prácticas, las habría fomentado, apropiándose de la capacidad del espacio para difundir principios ideológicos orientados hacia los intereses del estado (Tarragó y González 2000). No obstante y a diferencia de lo acontecido en Ampajango II, las huanca del poblado central de Rincón Chico no fueron alteradas. Los fechados obtenidos sugieren que las prácticas rituales tradicionales parecen haber perdurado hasta el efectivo control europeo del valle ${ }^{3}$.

\section{Recapitulación: Los Unos y los Otros}

Las evidencias de la presencia incaica en el sur del valle de Yocavil aparecen, a niveles microrregional e intrasitio, en una distribución heterogénea y, casi siempre, enmascaradas por la presencia mayoritaria de técnicas o materiales locales. Las cualidades de este registro arqueológico darían cuenta de las áreas con un valor particular para los objetivos políticos y económicos cuzqueños y que se juzgaron como adecuadas para ser desarrolladas mediante la inversión en infraestructura. Pero de igual modo estas cualidades reflejarían las condiciones organizativas vigentes a la llegada incai- 
ca, las cuales, a partir de cierto desarrollo, habrían sido funcionales a la administración central sin que fuera necesario invertir en obras más o menos monumentales.

A partir del modelo de organización que fuera planteado para los momentos previos a la llegada incaica, en el cual el poblado de Rincón Chico actuaba como cabecera política de un sistema de asentamiento que articulaba a otras instalaciones del sur del valle, no parece casual que sea en el área de acción inmediata del poblado en donde el registro imperial aparezca como más sutil, a diferencia de lo que se verifica en las localidades de la banda oriental del río Santa María, como Ampajango y Shiquimil. En Rincón Chico, las evidencias incaicas más claras tienden a concentrarse en el fondo del valle, es decir, en el sector más marginal al centro poblado ubicado en la serranía. Los conjuntos constructivos involucrados se alinearon sobre uno de los tramos subsidiario del camino incaico que atravesaba la zona, conectándolos, de tal forma, con las más importantes postas imperiales del área valliserrana del NOA (Hyslop 1990:254). Sugestivamente, este camino, en el área de nuestros estudios, engarzaba varios talleres de producción metalúrgica.

Sin quitar relevancia a la dinámica de la expansión imperial, consideramos que en el análisis de la ocupación de la región y de la variabilidad de su registro arqueológico es necesario considerar los condicionamientos derivados de las formaciones sociales locales. Desde esta óptica, los actores sociopolíticos del valle de Yocavil meridional no fueron sujetos pasivos que se alinearon automáticamente bajo los nuevos fundamentos y prácticas del poder. Por el contrario, es posible interpretar las transformaciones y las persistencias detectables en la producción de bienes y en la materialización ideológica en términos de múltiples competencias entre el gobierno cuzqueño, las jerarquías políticas locales y los diversos grupos con intereses sectoriales de las comunidades. En el proceso, la superestructura ideacional vigente, basada en antiguas concepciones surandinas, no habría sido permeada en su totalidad por el sistema estatal, resistiendo la colonización ideológica, entre otros mecanismos, a través de la adecuación y el rechazo de determinados aspectos de la lógica y los procedimientos de la tecnología dominante.

Por otro lado, los datos sugieren que la ocupación inca no habría incluido la implantación de grupos de poblaciones ajenas a la región (aunque es posible que sí hayan llegado de zonas cercanas y de la misma clase de organización como los de Belén en Quilmes y Fuerte Quemado), sino que la administración incaica se sirvió de la estructura de trabajo vigente y de la mano de obra ya en operación (González y Tarragó 2002a y b). En torno a este punto, encontramos significativa la correlación entre la alfarería santamariana y la mencionada Famabalasto Negro Grabado, tanto en épocas preincaicas como incaicas. Ello nos induce a proponer que este último estilo mantuvo valor simbólico y reconocimiento cultural, lo cual podría explicar que los administradores cuzqueños se hubieran interesado por difundir piezas Famabalasto Negro Grabado hacia asentamientos estatales externos al valle de Yocavil.

Algo similar parece haber ocurrido en metalurgia. Si bien tenemos evidencias que indican que a partir de la dominación incaica en la región comenzaron a manufacturarse objetos del catálogo imperial (González y Palacios 1996; González et al. 1999), así como lingotes, también sabemos que continuaron produciéndose con toda regularidad las piezas de reconocimiento local, tales como los grandes discos y las campanas ovales. De hecho, ha sido postulado que la administración cuzqueña, como parte de sus estrategias políticas, habría aprovechado el prestigio regional de estos bienes, apropiándose de los mecanismos de su distribución social, lo cual resulta coherente con la amplia representación surandina de los bronces santamarianos (Tarragó et al. 1997). De igual modo, si bien se introdujeron modificaciones en la organización de la producción metalúrgica, todos ellas tendientes a promover un aumento en la escala de salida de productos, fue mantenido el estilo tecnológico de procesamiento de los materiales y aún es posible que algunos procedimientos y el personal idóneo para llevarlos a cabo fueran trasladados a otros centros metalúrgicos fundados por el incario en los Andes del sur (González 1997).

Las modificaciones arquitectónicas en algunos de los espacios ceremoniales en operación tuvieron disímil alcance según se tratara del centro político o de instalaciones periféricas. La conocida conducta imperial de refundar el paisaje, como metáfora de ingreso a un nuevo orden social (Gallardo et al. 1995:169), está sugerida en las remodelaciones instrumentadas en el sector IV de Ampajango II. Allí, las remodelaciones aparejaron la 
sustracción a la comunidad local del control simbólico de las divinidades tutelares, al transformar la huanca ancestral en un ushnu encerrado dentro de una plaza de acceso restringido. Este sector, además, parece haber estado vigilado desde un reducto de cumbre, el cual, probablemente, se relacione con el Fuerte de Ampajango que se menciona en los documentos de las campañas represivas de Mercado y Villacorta, en el siglo XVII.

Sin embargo, en Rincón Chico las modificaciones en el amplio escenario ceremonial de la quebrada central no parecen haber estado dirigidas a interferir en las prácticas tradicionales, sino, por el contrario, a enfatizarlas. En este caso, todo apunta a indicar que la estrategia de los administradores estatales para captar la colaboración de la elite político-religiosa que manejaba los hilos de los sistemas productivos del sur del valle fue oficializar el esquema ritual vigente. Es pertinente mencionar que asentamientos cercanos, como Las Mojarras y Fuerte Quemado, presentan estructuras ceremoniales en altura, con características constructivas que se diferencian notablemente del caso de Rincón Chico y que sugieren mayor intromisión cuzqueña (González y Tarragó 2002a). Por otra parte, las huanca del piedemonte continuarán operando como en tiempos ante- riores, lo que podría señalar que algunos segmentos de la población reprodujeron el sistema de creencias ancestral.

La situación analizada, aún en su carácter exploratorio, proporciona elementos como para pensar que la confrontación entre el aparato ideológico estatal y el vigente en el área incorporada al Tawantinsuyu derivó en múltiples manifestaciones, cuyas características específicas sólo podrán ser establecidas a través de muchos y refinados estudios. Puede sostenerse que las concepciones que pugnaban por imponerse como dominantes hayan afectado de modo diferencial a los actores sociales, de acuerdo a su posicionamiento en la estructura político-económica y a la situación del conflicto inherente a una sociedad desigual. En este sentido, interpretamos que tanto los cambios como las continuidades que se advierten en la cultura material y en los espacios rituales nos están hablando de la multiplicación de fenómenos de resistencia cultural y señalan no sólo las estrategias desplegadas para la adecuación a un nuevo orden, sino también los esfuerzos para mantener y subrayar una diferenciación social y simbólica, representando el territorio de Yocavil meridional un interesante caso para el estudio de los mecanismos de resistencia a la dominación.

\section{Referencias Citadas}

Ambrosetti, J. B.

1904 El bronce en la región calchaquí. Anales del Museo Nacional de Buenos Aires 11:163-312.

Bruch, C.

1911 Exploraciones arqueológicas en las provincias de Tucumán y Catamarca. Revista del Museo de La Plata V, 19.

Cigliano, E. M.

1958 Arqueología de la zona de Famabalasto (Dto. Santa María, Prov. Catamarca). Revista del Museo de La Plata, Sección Antropología V:29-122.

Dearborn, D., M. Seddon y B. Bauer

1998 The sanctuary of Titicaca: where the sun returns to earth. Latin American Antiquity 9(3):240-258.

Earle, T. y T. D’Altroy

1989 The political economy of the Inka empire: the archaeology of power and finance. En Archaeological Thought in America, pp. 183-204. Editado por C. Lamberg Karlovsky. Cambridge University Press, Cambridge.

Gallardo I., F., M. Uribe R. y P. Ayala R. 1995 Arquitectura Inka y poder en el pukara de Turi, Norte de Chile. Gaceta Arqueológica Andina 24:151-171.

González, A. R.

1983 Nota sobre religión y culto en el noroeste argentino prehispánico. Baessler Archiv, Neue Folge 31: 219-282.
1992 Las Placas Metálicas de los Andes del Sur. KAVA, Berlin.

1998 Cultura La Aguada. Arqueología y Diseños. Filmediciones Valero, Buenos Aires.

González, L. R.

1992 Fundir es morir un poco. Restos de actividades metalúrgicas en el valle de Santa María, Pcia. de Catamarca. Palimpsesto. Revista de Arqueología 2: 51-70.

1997 Cuerpos ardientes. Interacción surandina y tecnología metalúrgica. Estudios Atacameños 14: 189-210.

1998 Tambo feroz. Nuevos datos sobre el asentamiento de Punta de Balasto y la ocupación incaica en el sur del valle de Santa María (Prov. de Catamarca). En Actas XII Congreso Nacional de Arqueología Argentina I, pp. 222-232. Ed. C. Díez Marín. La Plata.

2001 Tecnología y Dinámica Social. La Producción Metalúrgica Prehispánica en el Noroeste Argentino, Tesis Doctoral, Facultad de Filosofía y Letras, Universidad de Buenos Aires. Manuscrito en posesión del autor.

2002a A sangre y fuego. Nuevos datos sobre la metalurgia Aguada. Estudios Atacameños 24:21-37.

$2002 b$ Heredarás el bronce. Incas y metalurgia en el Noroeste argentino. Intersecciones en Antropología 3:55-68. Olavarría. 
González, L. R. y T. Palacios

1995 El volar es para los pájaros. Análisis técnico de dos piezas metálicas procedentes del valle de Santa María, pcia. de Catamarca. Arqueología 6:10-25.

González, L. R., E. Cabanillas y T. Palacios

1999 El pozo y el tumi. Arqueometalurgia del sur del valle de Yocavil. Cuadernos del Instituto Nacional de Antropología y Pensamiento Latinoamericano 18:207-222.

González, L. R. y M. N. Tarragó

2002a La ocupación incaica en el sur del valle de Yocavil (Noroeste argentino). Tawantinsuyu. Camberra, en prensa. 2002b Producción tecnológica e identidad durante el dominio incaico en el Noroeste argentino. Boletín de Arqueología PUCP, en prensa.

2003 Fantasmas en el paraíso. Aspectos de la dominación incaica en valle de Yocavil. Cuadernos 20. Instituto Nacional de Antropología y Pensamiento Latinoamericano, en prensa.

González, L. R. y E. Cabanillas

2003 Las campanas ovales del bronce del noroeste argentino prehispánico. Revista Andina 38:225-251.

Hyslop, J.

1990 Inka Settlement Planning. University of Texas Press, Austin.

Lechtman, $\mathrm{H}$.

1978 Temas de metalurgia andina. En Tecnología Andina, pp. 489-520 compilado por R. Ravines. IEP, Lima.

Márquez Miranda, F.

1946 Diaguitas. Inventario patrimonial arqueológico y paleoetnográfico. Revista del Museo de La Plata, NS III:5-300.

Montes, A

1959 El gran alzamiento diaguita (1630-1643), Revista del Instituto de Antropología I: 81-159.

Palmarzuck, V. y M. Manaziewicz

2001 Tiempos antiguos: centralización y estandarización en la producción de la cerámica Famabalasto Negro Grabado. Ponencia presentada en XIV Congreso Nacional de Arqueología Argentina, Rosario.
Pérez Gollan, J. A.

1999 Los suplicantes: una cartografía social. Temas de la Academia 2:21-36.

Tarragó, M. N.

1998 El patrimonio del valle de Santa María en peligro. En 50 años de aportes al desarrollo y consolidación de la antropología argentina. Homenaje a Alberto Rex González, pp. 205-253. Facultad de Filosofía y Letras-Fundación Argentina de Antropología, Buenos Aires.

1999 Chacras y pukara. Desarrollos sociales tardíos. En Los pueblos originarios y la conquista, Nueva Historia Argentina, 1, pp. 257-300. Sudamericana, Buenos Aires.

Tarragó, M. N., L. R. González y J. Nastri

1995 Las interacciones prehispánicas a través del estilo: el caso de la iconografía santamariana. Estudios Atacameños 14:223-242.

Tarragó, M. N., L. R. González, P. Corvalán, R. Doro, M. Manaziewicz y J. Peña

1999 La producción especializada de alimentos en el asentamiento prehispánico tardío de Rincón Chico, provincia de Catamarca. Cuadernos del Instituto Nacional de Antropología y Pensamiento Latinoamericano 18:409-427.

Tarragó, M. N. y J. Nastri

1999 Dimensiones de la complejidad santamariana. En Actas XII Congreso Nacional de Arqueología Argentina, II, pp. 259-264. Ed. C. Díez Marín. La Plata.

Tarragó, M. N., L. R. González y M. Tancredi

2001 El imperio contraataca. Nuevas evidencias en el sur del valle Yocavil. Ponencia presentada en XIV Congreso Nacional de Arqueología Argentina, Rosario.

Tarragó, M. N. y L. R. González

1998 La construcción social del espacio en Rincón Chico, Noroeste de Argentina. Ponencia presentada en $50^{\circ}$ Congreso Internacional de Americanistas, Varsovia.

Tartusi, M. y V. Núñez Regueiro

1992 Excavación de un montículo ceremonial tardío en el sector 1 del sitio StucTav5 (El Pichao). Publicaciones Instituto de Arqueología 2 (1):1-30.

\section{Notas}

1 La localidad de Rincón Chico ha proporcionado varios fechados preincaicos que comprenden muestras de alfarería Famabalasto Negro Grabado. Resultan particularmente diagnósticas las dataciones de piso en viviendas circulares donde estuvieron en uso escudillas de este estilo, $\mathrm{Vg}$. RCh

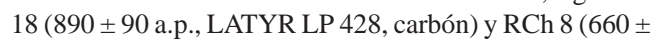
70 años a.p., LATYR LP 1491, carbón).
$340 \pm 130$ a.p., Beta 146374, carbón.

Los fechados obtenidos en las excavaciones de distintos peñascos son los siguientes: ML 25, $360 \pm 40$ a.p., Beta 162379, colágeno de hueso; ML 39, $400 \pm 30$ a.p., Beta 162380, colágeno de hueso; ML 7, $310 \pm 60$ a.p., LATYR LP 1390, carbón. 